\title{
A MEDIAÇÃO COMO INSTRUMENTO PACIFICADOR NOS CONFLITOS FAMILIARES*
}

\section{MEDIATION AS PACIFYING INSTRUMENT IN FAMILY CONFLICTS}

\author{
Rozane da Rosa Cachapuz \\ Taritha Meda Caetano Gomes
}

\begin{abstract}
Resumo: O presente artigo versa sobre os novos rumos do Direito Civil, em especial no tocante à família na atualidade e a aponta o instituto da Mediação de conflitos como caminho a ser alcançado. Analisa, primeiramente, o percurso histórico jurídico-social e familiar da sociedade e firma a Mediação como possibilidade. Introduz um arcabouço teórico acerca dos conflitos e em seguida apresenta a sistemática da mediação e seus fundamentos filosóficos. Por fim, expõe aplicação do instituto no cenário brasileiro.
\end{abstract}

Palavras-chave: Direito Civil. Família. Mediação. Conflitos.

Abstract: The present article treats about new routes of the Civil law, especially about family, in the present time and points to the Mediation of conflicts as a way to be reached. It analyzes, at first, the history of the institute and establishes the Mediation as a possibility. The present work set basis about the conflicts and after that, presents the philosophical system of mediation and its bedding. Finally, it exposes about the application of mediation in Brazil.

Keywords: Civil Law. Family. Mediation. Conflicts.

Este artigo é resultado de dissertação apresentada no Mestrado em Direito Negocial da Universidade Estadual de Londrina (UEL) no ano de 2006.

... Doutora em Direitos das Relações pela PUC-SP. Professora da Universidade Estadual de Londrina.

Mestre em Direito Negocial pela Universidade Estadual de Londrina. Especialista em Direito Civil e Processual Civil pela Universidade Estadual de Londrina. Mediadora e membro do grupo de mediação do Instituto para o Cuidado da Família em Londrina, PR. Advogada em Londrina. 


\section{LEITURA CRÍTICA DO MOMENTO HISTÓRICO}

\subsection{Panorama sócio-familiar e jurídico da contemporaneidade}

As significativas transformações nas diversas áreas existentes (científica, sociais, familiar) que ocorreram neste último século geraram na sociedade contemporânea uma certa disfunção e uma busca (velada ou aparente) por novas concepções, valores e paradigmas.

A atualidade convive com uma realidade de constantes modificações: a tecnologia avança, o consumismo se estende para todas as classes sociais de maneira avassaladora, o individualismo, a indiferença com o próximo, a globalização, a massificação social. A sociedade de tempos atrás difere significativamente da contemporânea.

O advento e a consolidação da sociedade industrial e as inúmeras revoluções deste último século embora tenham trazido recursos tecnológicos e transformadores no âmbito social, empregatício, relacional e jurídico deixaram de gerar o fortalecimento do ser humano. Ao contrário: nesta realidade, o indivíduo teria sido induzido a gozar de uma falsa liberdade. Isto porque, segundo o jusfilósofo José Elias Faria (1992, p. 136):

guiadas pela lógica monopolizadora e totalizante inerente ao desenvolvimento capitalista, a ciência e a técnica os teriam levado a se separar irreversivelmente da natureza. Não conseguindo conciliar historicamente experiência científica, expansão tecnológica e liberdade social, pois o processo cumulador, centralizador e concentrador decorrente da Revolução industrial teria hipostasiado o progresso da razão como valor autônomo, existente por si e indiferente a tudo, o espírito científico e a razão oriunda da Ilustração revelaram-se, com o tempo incapazes de neutralizar a angústia dos homens.

Semelhantemente, a família se transformou. A partir da segunda metade do século $\mathrm{XX}$, as conquistas femininas provocaram no ocidente mudanças significativas nas relações entre homens e mulheres e na estruturação familiar. A mulher, de forma mais incisiva passa a ter papel no mercado de trabalho e conseqüentemente dupla jornada - casa e trabalho.

O fenômeno do divórcio cresceu nos EUA a partir da década de 50, e, no Brasil, após o advento da lei do Divórcio em 1977, houve um redesenhar da família contemporânea. No final da década de 80 têm-se as primeiras referências sobre pesquisas clínicas realizadas com crianças e adolescentes que passaram pelo divórcio dos pais: evidências devastadoras e prolongadas conseqüências (SCHABBEL, 2005). 
Os casamentos são mais tardios e não arranjados. A família nuclear tradicional começa a tornar-se uma exceção em um universo marcado pelo trinômio casamento, separação e recasamento (SCHABBEL, 2005).

Em dados intrigantes, o IBGE demonstra que em metade dos lares brasileiros não mais existe o modelo clássico: pai, mãe e filhos do mesmo casamento (PEREIRA, 2003, p. 87).

Há mais famílias se formando a partir de novas bases. Isto é um desmembramento do que antes era uma única unidade familiar e para que se tenha novas "modalidades" de famílias, ou novas formas de entidades familiares, nas palavras de Gustavo Tepedino (1999). O casamento deixou de ser indissolúvel e os métodos contraceptivos multiplicaram-se.

Elizabeth Carter (1995) afirma que segundo o United States Census Bureau, a porcentagem de divórcios nos Estados Unidos é mais elevada entre pessoas que estão no segundo casamento. Isto significa que um quinto dos americanos que hoje têm trinta anos irá passar, não somente por um, mas por dois divórcios. E mais, o fim do segundo casamento acontece em menos tempo: depois de apenas quatro, em média, contra sete anos após o primeiro casamento. Esta é a denominada nova família contemporânea.

Neste contexto de grande transformação social, tem-se a percepção de que o Direito, de igual sorte, alterou-se e ainda clama por mudanças. Os dogmas que outrora foram suficientes, hoje não mais o são. No âmbito específico do Direito Civil, algumas modificações foram sentidas no decorrer da metade do século $\mathrm{XX}$, especialmente após a percepção da insuficiência dos paradigmas da sociedade industrial.

O arcabouço jurídico tradicional - formalista, patriarcal e individualista não corresponde aos anseios e necessidades da vida contemporânea, nem mais conseguiu fornecer soluções aos novos problemas emergentes (WOLKMER, 2001). Este desarranjo jurídico produziu um repensar dos padrões.

\subsection{Insuficiência e necessidade de novos paradigmas}

José Saramago (1999) ao encerrar o ciclo de Estudos da Universidade de Coimbra "Perspectivas do Direito no Início do Século XXI” teceu uma interessante conto denominado "O Direito e os Sinos". Em linhas gerais, conta que um camponês em Florença, ao procurar resolver seu conflito por diversas maneiras - judiciais e extrajudiciais - não obteve resposta. Assim, dirigiu-se ao centro da vila onde habitava e tocou os sinos a finados. Questionado por seus conterrâneos sobre quem tinha falecido, informou ter sido o Direito, pois não havia obtido dele qualquer auxílio. 
Ao meditar sobre o conto, Saramago apresenta o seguinte apontamento (1999, p. 35):

Suponho ter sido esta a única vez que, em qualquer parte do mundo, um sino, [...] chorou a morte da Direito. Nunca mais tornou a ouvir-se aquele fúnebre dobre da aldeia de Florença, mas a Justiça continuou e continua a morrer todos os dias. Agora mesmo, neste instante em que vos falo, longe ou aqui ao lado, à porta da nossa casa, alguém o está matando. De cada vez que morre, é como se afinal nunca tivesse existido para aqueles que nela tinham confiado, para aqueles que dele esperavam o que da Justiça todos temos o direito de esperar: justiça, simplesmente justiça.

Não qualquer justiça ou uma justiça distante, ao contrário, uma justiça companheira do ser humano. E finaliza o autor em palavras poéticas que lhes são comuns:

uma justiça para quem o justo seria o mais exacto e rigoroso sinónimo do ético, uma justiça que chegasse a ser tão indispensável à felicidade do espírito como indispensável à vida é o alimento do corpo. Uma justiça exercida pelos tribunais, sem dúvida, sempre que a isso os determinasse a lei, mas também, e sobretudo, uma justiça que fosse a emanação espontânea da própria sociedade em acção, uma justiça em que se manifestasse, como um iniludível imperativo moral, o respeito pelo direito a ser que a cada ser humano assiste. (SARAMAGO, 1999, p. 39).

O mundo contemporâneo freqüentemente convive com a descrença no Direito. O Direito, em alguns momentos, encontra-se em descompasso com sua proposta. Por vezes, inexiste no universo jurídico a relevância constitucional dada à dignidade da pessoa humana, nem qualquer cuidado com o indivíduo em si. Há um desajuste entre a estrutura social e a superestrutura jurídica. É possível que muitos daqueles que recorreram ao judiciário, especialmente nos conflitos familiares, ainda que vencedores frustraram-se com o sistema.

Antônio Carlos Wolkmer (2005), neste sentido, assim afirma:

Assinala-se que a crise que se abate sobre o arcabouço jurídico tradicional está perfeitamente em sintonia com o esgotamento e as mudanças que atravessam os modelos vigentes nas ciências humanas. Adverte-se que as verdades metafísicas e racionais que sustentaram durante séculos as formas de saber e de racionalidade dominantes, não mais mediatizam as inquietações e as necessidades do presente estágio da modernidade liberal-burguêscapitalista. [...] abrindo espaço para se repensar padrões alternativos de referência e legitimação.

Leciona ainda Wolkmer (2005) que o Direito positivo estatal encontra-se 
muitas vezes impotente e não atende de forma geral o universo complexo e dinâmico das atuais sociedades de massa. Estas sofrem profundas contradições sociais e instabilidades, que refletem em crises de legitimidade, produção e aplicação da justiça.

Por fim, assevera Wolkmer (2005) que se torna obrigatório discutir a "crise dos paradigmas" na esfera específica do fenômeno jurídico. A crise no âmbito do Direito significa o esgotamento e a contradição do paradigma liberal-individualista que não consegue mais dar respostas aos novos problemas emergentes.

Por tudo isso, tornou-se (e ainda se torna) imprescindível a reorganização dos paradigmas jurídicos. Estes novos paradigmas estão diretamente ligados à complexidade de conflitos das relações contemporâneas, que produzem efeitos no Direito. Diante desta complexidade, não se pode mais conceber um modelo único, ainda que abstrato (HIRONAKA, 2001).

Neste sentido, assevera Fachin (2004)

Ao final do século XX, assevera portanto, séculos depois da vigência do estatuto moderno fundamental da apropriação dos bens, da titularidade e do sujeito - o Código Napoleônico - esboça uma tentativa de superação do sujeito abstrato, com a construção do sujeito concreto, agregando-se àquela noção de cidadania. Eis aí o porvir do Direito Civil. (p. 188).

$\mathrm{Na}$ sociedade contemporânea, a sistemática tradicional carece de novo perceber e novos paradigmas. "Outro tempo, novos conceitos. A crise pressupõe idéia de superação, a expressão segmentada que tem como premissa a possibilidade de encontrar sentido em outras perspectivas", afirma com propriedade Luis Edson Fachin (2003, p. 318).

Urgem respostas eficazes para atender aos clamores populares por justiça e dignidade, bem como soluções eficazes aos conflitos sociais. E estas podem se dar através da busca por soluções alternativas, que valorizem o ser humano, instrumentalizem o direito atingir seu escopo.

\section{NOVOS PARADIGMAS: POSSIBILIDADE DA MEDIAÇÃO DE CONFLITOS}

O conceito de administração da justiça tem sido historicamente monopólio do estado que de algum modo, restringiu a capacidade das partes resolverem seus próprios conflitos. O ser humano perdeu a habilidade de resolver seus problemas e lançou ao estado a decisão de sua própria vida e aos advogados o confronto.

Os juizes carecem de formação humanista, encontram-se sobrecarregados e não conseguem analisar profundamente cada caso. Os processos são lentos e desgastantes e não conseguem promover a paz. 
O Direito tem vislumbrado novos paradigmas que busquem atender à realidade social, tais como a dignidade da pessoa humana, exposto no Art.1 ${ }^{\mathrm{a}}$, III da CF, a autonomia privada, a função social, o afeto, dentre muitos outros. mais humanizado e interessado na pessoa humana - e não no indivíduo sujeito de direito - como o seu verdadeiro centro: "um Direito mais ético, mais composto com o sentir do que com a razão, mais digno, mais socializado, mais corajoso e fiel, mais despojado de arcabouços meramente patrimoniais, mais permeável ao afeto, enfim" (HIRONAKA, 2001, p. 8). Um Direito que atenda ao clamor da sociedade e que se aproxime das práticas sociais cotidianas.

Para minimizar os efeitos disfuncionais da realidade anteriormente narrada, é possível considerar uma possibilidade (FARIA, 1992, p. 90):

promover a diversificação das jurisdições especializadas, em nome tanto da expansão quantitativa dos litígios quanto da crescente complexidade técnica e material dos processos e a desformalização de determinadas controvérsias em áreas específicas da justiça civil (consumidores, vizinhança, responsabilidade civil, família), pela ênfase às arbitragens, mediações, conciliações extrajudiciais.

Em Congresso na Universidade de Coimbra, Caldas (1999, p. 16) afirmou que:

Impõe-se ir construindo meios operacionais de graduação de complexidade na judicialização e simultaneamente encontrar modelagem que permita transferir para arbitragem, a mediação, o juízo de paz e de eqüidade uma plêiade de conflitualidades que não carecem de judicialização.

Parece, portanto, haver forte inclinação ao deslocamento de determinadas questões para as modalidades alternativas de resolução de conflitos.

Como forma de concretizar estes novos valores, tem-se a possibilidade das ADR - Alternatives Disputes Resolutions. O termo ADR a princípio foi utilizado nos Estados Unidos (e países da common law), e se referia a todas as formas de processos de resolução de disputas, sem intervenção de autoridade judicial. (SERPA, 1999, p. 356).

Podem ser conceituados como modalidades para a finalização de conflito entre indivíduos ou grupos. Pode ainda se referir à forma de solucionar desacordos de maneira satisfatória, economicamente viável para partes, de modo a evitar o processo adversarial.

São modalidades dos ADR dentre muitos a conciliação, negociação, a arbitragem e a mediação, objeto de estudo do presente artigo.

A mediação surge como meio consolidador do princípio da dignidade da 
pessoa humana e como resgate da autonomia privada - decisória - das partes. Recupera esta autonomia dos sujeitos e os transforma em co-autores deste mesmo Direito.

Longe de almejar ser substituto do judiciário ou fornecer soluções rápidas ao conflito, a mediação é uma mudança paradigmática: promove uma cultura de humanização de vínculos.

A mediação remonta à Antigüidade. Nas palavras de Maria de Nazareth Serpa (1999, p. 67):

Alternativa para solucionar disputas não é novidade. Talvez seja moderno chamar alternativa o que, em todos os tempos e lugares, foram maneiras cotidianas e imediatas de resolver problemas entre as pessoas. Começando pelo diálogo até a guerra, são incontestáveis e informais os métodos utilizados pela humanidade para pôr fim aos seus conflitos. Os tribunais sempre foram a última opção. ADR não é panacéia do século XX. É a institucionalização do que vem sendo feito, [...] em matéria de resolução de conflito.

Em Roma, havia a figura do árbitro ou mediador o direito "previa o procedimento in iure e o in iudicio que significam na presença do juiz, o primeiro, e do mediador ou árbitro, segundo Cachapuz (2005, p. 34).

Entre os judeus, chineses e japoneses a mediação sempre se fez presente. A figura do mediador podia ser institucional ou natural. A primeira forma decorrente de uma hierarquia na organização da vida comunitária (poder delegado) e a segunda como expressão do exercício da cidadania.

$\mathrm{Na}$ China antiga havia a prática da mediação, baseada nos ensinos de Confúcio. Há ainda uma instância institucional de mediação que constitui uma etapa obrigatória de acesso à justiça (BARBOSA, 2002).

No Japão, de igual sorte, utilizou-se e ainda utiliza-se da mediação, com a figura do mediador em cada comunidade. Existe o denominado chote, que consiste em confiar a uma terceira pessoa ou uma comissão formada por um magistrado e dois ou mais conciliadores, se necessário. Os conciliadores são nomeados pelo Supremo Tribunal, para o período de dois anos. Devem ter entre 40 e 70 anos, qualificação técnica para a função, por competência ou personalidade, conforme assevera Águida Arruda Barbosa (2002, p. 48). Esse instituto, atualmente, está regulado por lei desde dezembro de 1947.

Semelhantemente, nas tribos africanas havia a figura dos "moots", que eram reuniões públicas ou privadas com fim a resolver conflitos.

No modelo ocidental, a mediação ressurge no EUA como forma de resolução rápida ${ }^{1}$, em razão da crescente demanda do contencioso em massa e como uma justiça de segunda classe.

Mas logo, percebeu-se seus benefícios e esta se espalhou para a Inglaterra e 
França. Inclusive, vale salientar que na França já houve a reforma do CPC, incluindo a mediação. Os casos solucionados pela mediação nos EUA chegam a 90\% no Norte Califórnia (DAVIS, 2003, p. 50) e, no mínimo, 50\% em Chicago, conforme afirma a mediadora Lynn Jacob (2006). Semelhantemente no Canadá há grande difusão do instituto.

$\mathrm{Na}$ América latina, a mediação surgiu primeiramente na Argentina, $\mathrm{Na}$ América Latina, a mediação foi introduzida primeiramente na Argentina, quando houve o estabelecimento da obrigatoriedade de passagem em Câmaras de mediação antes do ingresso no judiciário. Em 1995, a lei 24.573 buscou descongestionar o judiciário e estabeleceu a mediação obrigatória às ações judiciais.

\section{CONCEITO, FUNDAMENTOS, VALORES DA MEDIAÇÃO}

Mediação procede do latim mediare - mediar, dividir ou intervir. (SCHABBEL, 2002). Luis Alberto Warat (1999, p. 5) define a mediação como:

uma forma ecológica de resolução dos conflitos sociais e jurídicos; uma forma na qual o intuito de satisfação do desejo substitui a aplicação coercitiva e terceirizada de uma sanção legal. A mediação como uma forma ecológica de negociação ou acordo transformador das diferenças.

Já John M. Haynes (1996, p. 20), a conceitua como

um processo no qual uma terceira pessoa - o mediador - auxilia os participantes na resolução de uma disputa. $\mathrm{O}$ acordo final resolve o problema com uma solução mutuamente aceitável e será estruturado de modo a manter a continuidade das relações das pessoas envolvidas no conflito.

Deste modo, a mediação pode ainda ser conceituada como recurso alternativo de resolução de conflitos, utilizado para solucionar situações de litígio, confidencial, voluntário e com o auxílio de um terceiro imparcial. É a busca pelas próprias partes de soluções para seus interesses, através do resgate da comunicação.

Há a reorganização do problema a partir de suas próprias singularidades, bem como da capacidade individual da parte de se relacionar com as novas posições adquiridas.

${ }^{1} \mathrm{O}$ termo mediação familiar foi desenvolvido por D. J. Coogler, advogado de Atlanta que, em 1974, inaugurou um escritório de prática privada de mediação familiar, vindo a publicar a teoria da experiência em 1978, sob o título de Structured Mediation in Divorce Settlement. A iniciativa é tão aplaudida que, em 1982, já havia mediadores familiares em 44 estados americanos. 
A mediação possui natureza contratual, visto que serem duas ou mais vontades orientadas para um fim comum de produzir conseqüências jurídicas, extinguindo ou criando direitos. Esta natureza encontra-se fundamentada e embasada nos princípios da boa-fé, que impõe a todos o dever de lealdade. Tem como fonte também a autonomia privada. É procedimento informal, voluntário, consensual (BRAGA, 1999).

A mediação não julga ou procura culpados - réus e autores -, mas sim, conforme discorre Juan Carlos Vezzulla, (1999, p. 114) antes,

analisa o passado para que fiquem esclarecidas as inter-relações e sejam trazidos à tona os desejos do presente e do futuro. Seja qual for o relacionamento entre parte (o contrato) o importante na mediação é estabelecer qual deveria ser o contrato (o relacionamento) atual entre alas, que as satisfaça plenamente, e não quem quebrou o contrato passado.

Há possibilidade, portanto, de se ter duas figuras: ganhador e ganhador. Este pensamento não é comum ao contexto atual, acostumado ao maniqueísmo e a reflexão linear. Neste sentido afirma Dora F. Schintman (1999 apud SALES, 2004, p. 29):

Nossa cultura privilegiou o paradigma ganhar-perder, que funciona como uma lógica determinista binária, nas qual a disjunção e a simplificação limitam as opções possíveis. A discussão e o litígio - como métodos para resolver diferenças - dão origem a disputas nas quais usualmente uma parte termina ganhadora e outra perdedora. Essa forma de colocar as diferenças empobrece o espectro de soluções possível, dificulta as relações entre as pessoas envolvidas e gera custos econômicos, afetivos e relacionais.

É preciso ainda destacar que a mediação pode ser vista como uma forma de prevenir os conflitos. Isto porque, insere no sistema daquelas partes a realidade e a possibilidade do acordo. A mediação, neste sentido, pode ser traduzida como aquela que minimiza os efeitos da escalada do conflito, em especial, nas demandas familiares e retoma a capacidade decisória das partes e a conseqüente responsabilização das mesmas.

\section{PROCEDIMENTO}

Existem acerca da mediação inúmeros teorias sobre o procedimento do instituto. Adotou-se para o presente artigo o lecionado por John Haynes e Marilene Marodin (1996).

Para estes autores, a mediação possui os seguintes passos: 1) normalização, 2) mutualização, 3) foco no futuro; 4) resumo e 5) formulação de hipótese e finaliza 
o acordo escrito e leva à homologação judicial. Analisar-se-á cada uma das técnicas apresentadas.

Ao tempo em que as partes chegam à etapa de litígio, comumente, trazem consigo a idéia de que seu conflito é anormal, único e insolúvel. Tentam convencer o mediador de que sua história é ímpar e que a solução dada por ela torna-se a única cabível. Logo, importa ao mediador eliminar as singularidades do conflito e normalizar a situação. Assim, a situação vivida torna-se comum convencê-las que seus conflitos são comuns e por conseqüência passível de solução.

Semelhantemente, as partes tendem a responsabilizar o outro pelo litígio e se eximindo de toda culpa. Cabe ao mediador, nesta hipótese, auxiliar os mediados a deixarem suas definições individuais e a vislumbrarem uma idéia mútua, redefinindo o conflito ${ }^{2}$. Tomam-se as palavras de John Haynes e Marilene Marodin (1996, p. 20), para exemplificar tal situação:

Em caso de custódia de filho, o pai pode queixar-se: 'Mas os filhos precisam de seu pai.' A mãe responde rapidamente: 'Mas eles precisam de sua mãe mais ainda.' O mediador intervém: 'Eu presumo que eles precisam de ambos.' Esta situação não contradiz o que cada um deles falou. Simplesmente coloca seu problema como sendo mútuo. As opções para resolver definições mútuas de problemas inclinam-se a ser soluções mútuas.

Uma vez tomados estes passos, devem as partes enfocar o futuro. As partes chegam ao mediador visualizando o passado. Sua disputa é sobre o passado. No entanto, este não deve ser o foco da mediação. Os fatos pretéritos são imutáveis, não se pode alterá-los.

O mediador, portanto, não deve buscar encontrar réus e autores, tampouco perscrutar em demasia o passado das partes. Ao contrário, leva-as a chegarem a soluções reais, enfocando no futuro. Vale salientar que se torna árduo queixar-se sobre algo que não se conhece, a saber, o futuro.

Após esta compreensão, o mediador move a sessão através do resumo. Com isso, faz com que as partes percebam a situação real em que se encontram. O mediador ao fazer resumo, deve lembrar-se de que não é um magistrado ou um terapeuta. Ao contrário, é mister, nesta etapa, focalizar somente naquilo que auxiliará as partes a chegarem num senso comum, para que se obtenham dados que formarão a linha de questionamento.

${ }^{2}$ Quando as partes são levadas a ver suas posições iniciais sob a ótica da mutualização e da normalização, há uma redefinição destas posições. Pode-se, portanto, instrumentalizar o encontro de seus próprios e reais interesses. 
Tem-se ainda a formulação das hipóteses, que auxilia o profissional a manter o foco em sua relação profissional com o cliente, escolher a linha adequada de questionamento e selecionar a questão específica mais útil dentro desta linha.

O mediador pode formular sua hipótese sobre três prismas: a) o problema a ser resolvido na negociação, b) os objetivos dos clientes e c) seu comportamento ao negociar (o profissional não é mais um advogado ou terapeuta, é um mediador). O último ponto deve ser a redação do termo de acordo e a homologação judicial, se necessário.

Por fim, vale salientar que existem ciclos no procedimento de mediação. Para cada conflito, a dinâmica inicia-se novamente, resolvendo as questões de modo individual, se necessário.

\section{APLICAÇÃO}

A mediação pode ser aplicada em quase todas as áreas, sendo seu universo de atuação bastante vasto ${ }^{3}$. Em todos estes se pode humanizar os conflitos ao trazer respeito aos sentimentos das partes, ao valorizar a escuta, ao perceber a dinâmica sistêmica do conflito.

A mediação pode alcançar todas as questões patrimoniais na área cível: contratos, responsabilidade civil, condomínio, direitos autorais, entre outras muitas possibilidades. Especificamente no âmbito consumerista, Amélia Soares da Rocha (2003, p. 45) afirma:

a mediação, assim, pelo seu caráter de transformação efetiva, é instrumento implicitamente idealizado para a consecução de um mercado de consumo mais justo e equilibrado, ratificado por sua vertente educativa, bem como de maneira explícita ao se interligar a realização dos direitos dos consumidores com as formas alternativas de solução de conflitos.

$\mathrm{Na}$ esfera comercial e empresarial, aplica-se mediação em controvérsias entre sócios, dissoluções de sociedades, divergências entre clientes e fornecedores, questões organizacionais, joint-ventures, projetos de construções, franquias, leasing, factoring.

No tocante a centros comunitários, aplica-se a questões diversas que envolvam a manutenção ou a melhoria da convivência. Nas comunidades em determinados

${ }^{3}$ De forma especial, nos Estados Unidos, segundo Maria de Nazareth Serpa (1999), tem-se destaque para área civil e comercial, com ênfase na demanda contratual, nas questões trabalhistas, de família - inclusive, com a especialidade de mediação em divórcio -, conflitos de vizinhança e internacionais. 
países como Inglaterra e Estados, possuem, nos seus centros, mediadores especializados.

Politicamente, tanto no internacional ou nacional, consagra-se a mediação no que tange à articulação e negociação de interesses de convivência. Cabe sua aplicação no âmbito internacional, como soluções de conflitos vinculados ao Mercosul, e também questões vinculadas ao meio ambiente, na qual há o estabelecimento de diálogos entre órgãos públicos, comunitários e judiciais.

Não obstante todas estas aplicações, no trato das questões familiares que a mediação encontra vereda ampla e valor significativo, como se verificará de maneira mais aprofundada no item abaixo.

\subsection{Mediação familiar}

Os problemas familiares, antes de serem de direito, são afetivos, emocionais e relacionais, antecedidos de sofrimento e dor. Dizem respeito a casais que, além da ruptura, devem imperativamente conservar as relações de pais, em seu próprio interesse e no interesse das crianças.

Abrangem a questão da parentalidade - guarda, visitas, alimentos e afeto (novo paradigma do direito de família contemporâneo) - e da conjugalidade separação e divórcio e outras conflitos que decorrem da área da família.

Em linhas gerais, a mediação familiar traz consigo inovações sobre o como: como definir e pacificar um conflito familiar; como restaurar a comunicação entre casais em processo de separação; como compreender o questionamento sobre a parentalidade (BARBOSA, 2002); enfim, como humanizar as relações.

Ademais, segundo o estudo de Danièle Ganância (2001, p. 15), a mediação familiar possui um tríplice escopo: pacificar o conflito, responsabilizar as partes e permitir a continuação das relações de co-parentalidade.

A pacificação do conflito refere-se ao despertar das partes e dos operadores do direito da responsabilidade na reorganização da família, revendo a ruptura do vínculo conjugal. Este 'despertar' visa criar um novo modelo: o que antes revelava uma litigiosidade transforma-se em uma família pós-divórcio.

Assim, tem-se uma reorganização familiar e passam a compreender sua nova estrutura: de pais de família nuclear (pai, mãe, filhos) para binuclear (pai e filhos, mãe e filhos). Fixam-se, ainda os papéis dos antigos cônjuges: deixam conjugalidade (marido e esposa) e permanece a parentalidade (pais e filhos), distinguindo-os entre si. Isto porque, os cônjuges perdem as funções maritais.

A percepção dos benefícios da mediação no trato dos conflitos familiares é indispensável para respostas aos novos paradigmas do Direito. A família transformou-se e carece de tratamento que corresponda a sua realidade e que 
possibilite o resgate da afetividade e do sentimento das partes envolvidas. É preciso que haja a valorização do ser humano e da entidade familiar, isto através da mediação.

\section{A MEDIAÇÃO NO CENÁRIO BRASILEIRO}

No Brasil, a mediação tem se desenvolvido significativamente. Em dezembro de 1998 a Deputada Zulaiê Cobra Ribeiro elaborou Projeto de Lei n. atualmente sob o n⿳⺈.9. 94/02 no Senado Federal, que já tramitou pela Comissão de Justiça, pendente de votação e aprovação para se tornar a lei nacional para instituir a Mediação no Brasil. Conforme leciona Águida Arruda Barbosa (2002), a inspiração que se prestou de êmbolo a essa iniciativa foi o estudo da inserção da mediação no Código de Processo Civil da França, que recepcionou o instituto em reforma processual de 08 de janeiro de 1995.

Semelhantemente, cabe perceber o esforço governamental no sentido da educação para a mediação. Inserido nas recomendações do Ministério da Educação - Secretaria de Educação Superior, em junho de 2001, item 5, letra C, II - Organização Didático-Pedagógica, dos Padrões de Qualidade do Curso de Direito a mediação deve ser desenvolvida pelo núcleo de prática jurídica dos cursos de Direito.

Em Santa Catarina, o Tribunal de Justiça realiza projeto de aplicação da mediação nos casos de conflitos familiares, que foi regulamentado pela resolução 11/01. Os atendimentos podem acontecer antes do ajuizamento da ação ou pelo encaminhamento do juiz. São gratuitas e desenvolvidas equipes multidisciplinares (advogados, psicólogos, assistentes sociais). A mediação familiar do TJSC funciona em diversas cidades do Estado, dentre elas: Florianópolis, Tubarão, Joinville, Chapecó, etc.

Em Porto Alegre, Rio Grande do Sul, a psicóloga e mediadora Marilene Marodin (2003) desenvolve juntamente com a Vara da Infância e Juventude trabalho inovador de mediação entre adolescentes infratores e as vítimas agredidas. O resultado tem sido muito satisfatório. Outros estados brasileiros como São Paulo, Maranhão vem dando início à prática da mediação em seus tribunais.

Em Londrina, alguns movimentos estão sendo feitos buscando despertar a prática da mediação local. A organização não governamental "Instituto para o Cuidado da Família” visa desenvolver o estudo e atendimento da mediação, através de uma equipe reflexiva compostas por advogados, psicólogos e assistentes sociais. Os casos atendidos são privados ou encaminhados pelo juiz da $2^{\underline{a}}$ Vara de Família e muitos têm obtido resultados satisfatórios. 
Encontra-se em fase de oficialização o convênio entre as varas de família e o Instituto para o Cuidado da Família, no qual haverá encaminhamento constante de casos para a mediação.

\section{CONCLUSÃO}

À guisa da conclusão, é possível defender que a mediação é necessária aos clamores sociais da atualidade e um instrumento eficaz para atender estes anseios.

Longe de almejar ser substituto do judiciário ou fornecer soluções rápidas ao conflito, a mediação é uma mudança paradigmática: promove uma cultura de humanização de vínculos. Para tanto, se fazem necessárias alterações na cultura e mentalidade da sociedade, cuja tradição encontra-se alicerçada nos litígios e na transferência do conflito, fundada no pensamento paternalista: Estado como solucionador principal dos conflitos individuais.

Por fim, pode-se concluir que a mediação permite a implementação de um Direito mais humano e ético; voltado resgate pessoal e social. E almeja a instauração de uma cultura que prime pela paz eleve o indivíduo, verdadeiramente, à dignidade em toda sua extensão.

\section{REFERÊNCIAS}

BARBOSA, Águida Arruda. Mediação Familiar. Instrumento Transdisciplinar em Prol da Transformação dos Conflitos Decorrentes das Relações Jurídicas Controversas, 2003. Dissertação (mestrado em Direito) - Faculdade de Direito da Universidade de Direito de São Paulo, São Paulo. abr. 2003.

A mediação na França Hoje. Boletim IBDFAM. E-mail recebido em: 4

BRAGA, Adolfo. Os advogados, os conflitos e a mediação. In: OLIVEIRA, Ângela (Coord. ). Mediação - Métodos de Resolução de Conflitos, n. 1. São Paulo: LTr, 1999.

CACHAPUZ, Rozane da Rosa. Mediação nos conflitos e Direito de Família. Curitiba: Juruá, 2005.

CALDAS, Júlio de Castro. Perspectivas da realização do Direito e dos Valores que ele integra e veicula no início do terceiro milénio. In: NUNES, A. J. Avelãs et al. Perspectivas do Direito no início do século XXI. Coimbra: Coimbra Editora, 1999.

CARTER, E. Famílias Reconstituídas: a criação de um novo paradigma. São Paulo: Summus. 1995. 
DAVIS, Edward. Mediação no direito comparado. In: DELGADO, José et al. Mediação: um projeto inovador. Brasília: Conselho da Justiça Federal, Centro de Estudos Jurídicos, 2003. (Série Cadernos do CEJ; v. 22).

FACHIN, Luiz Edson. Teoria crítica do Direito Civil. Rio de Janeiro: Renovar. 2003.

FARIA, José Eduardo C. de O. Justiça e Conflito: Os juizes em face dos novos movimentos sociais. 2. ed. São Paulo: Rev Tribunais. 1992.

. Qual o futuro dos direitos? Estado, mercado e justiça na reestruturação capitalista. São Paulo: Rev Tribunais. 2002.

GANANCIA, Danièle. Justiça e mediação familiar: uma parceria a serviço da co-parentalidade. Revista do Advogado, São Paulo, n. 62, p. 7-15, mar. 2001.

HAYNES, John M.; MARODIN, Marilene. Fundamentos da mediação familiar. Porto Alegre: Artmed, 1996.

HIRONAKA, Giselda Maria Fernandes Novaes. Família e casamento. Revista do Advogado, São Paulo, n. 62, p. 16-24, mar. 2001.

. Direito Civil Brasileiro: de Clóvis Bevilacqua a Miguel Reale. A visão Contemporânea, a transição legislativa e as tendências para o Século XXI. Disponível em: 〈“http://www.mudojuridico.adv.br"〉. Acesso em: 15 out. 2005.

PEREIRA, Paula. A nova família. Época, Rio de Janeiro, n. 293, p. 82-89, 29 dez. 2003.

ROCHA, Amélia Soares da. A mediação e o direito do consumidor. In: SALES, Lilia Maia de Morais (Org.). Estudos sobre a mediação e arbitragem. Rio de Janeiro: ABC Editora, 2003.

SALES, Lília Maia de Morais. Justiça e mediação de conflitos. Belo Horizonte: Del Rey, 2004.

SARAMAGO, José. O direito e o sinos. In: NUNES, A. J. Avelãs et al. Perspectivas do Direito no início do século XXI. Coimbra: Coimbra Editora, 1999.

SCHABBEL, Corinna. Mediação Escolar de Pares. São Paulo: WHH, 2002.

. Relações familiares na separação conjugal: contribuições da mediação. Psicologia: Teoria e Prática, São Paulo, v. 7, n. 1, p. 13-20, 2005.

SERPA. Maria Nazareth. Teoria e prática da mediação de conflitos. Rio de Janeiro: Lúmen Iuris, 1999. 
TEPEDINO, Gustavo. Temas de Direito Civil. Rio de Janeiro:Renovar. 1999.

VEZZULLA, Juan Carlos. A mediação. O mediador. A justiça e outros conceitos. In: OLIVEIRA, Ângela (Coord. ). Mediação - Métodos de Resolução de Conflitos, n. 1. São Paulo: LTr, 1999.

WARAT, Luiz Alberto. Ecologia, psicanálise e mediação. In: . (Org.). $E m$ nome do acordo. 2. ed. Argentina: Almed, 1999.

WOLKMER, Antônio Carlos. Pluralismo jurídico: novo paradigma de legitimação. Mundo Jurídico, 30 set. 2005. Disponível em: <http:// www.mundojuridico.adv.br/sis_artigos/artigos.asp?codigo=646>. Acesso em: 15 out. 2005.

. Pluralismo jurídico: fundamentos de uma nova cultura no Direito. 3. ed. rev. e atual. São Paulo: Alfa-Omega, 2001. . Introdução ao pensamento jurídico crítico. 4. ed. São Paulo: Saraiva, 2002. 